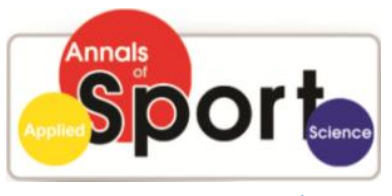

www.aassjournal.com

ISSN (Online): 2322 - 4479

ISSN (Print): 2476-4981

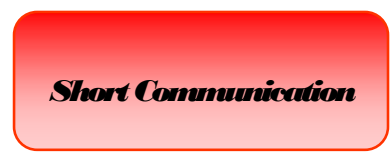

www.AESAsport.com

Received: 20/03/2016

Accepted: 10/06/2016

\title{
Alpha-actinin-3 R577X Polymorphism Profile of Turkish Professional Hip-Hop and Latin Dancers
}

\author{
${ }^{1,2}$ Korkut Ulucan ${ }^{*},{ }^{1}$ Betul Biyik, ${ }^{1}$ Sezgin Kapici, ${ }^{2}$ Canan Sercan, ${ }^{1}$ Oznur Yilmaz, ${ }^{1}$ Tunc Catal
}

${ }^{1}$ Üsküdar Univerity, Haluk Turksoy Sok. No:14, Altunizade, Üsküdar, İstanbul, Turkey. ${ }^{2}$ Marmara University, BAsibuyuk Yolu 9/3 MAltepe Saglık Yerleşkesi, MAltepe, Istanbul, Turkey.

\begin{abstract}
Actins are small globular filaments functioning in cell processes like muscle contraction, and stabilized to the sarcomeric Z- discs by actin binding proteins (actinins). One of the important gene coding for actin binding proteins in fast twitch fibers is alpha- actinin- 3 (ACTN3). In this research, we have conducted a gene profile study investigating the genotype and allele distributions of ACTN3 R577X polymorphism in Turkish professional hip- hop and latin dancers and compared them to non-dancers as a control group. 30 professional dancers and non-dancers were recruited for the study. A genotyping procedure was carried out by a newly introduced four-primer PCR methodology. For statistical analysis, the Chi-square test was used to compare data between the groups $(\mathrm{p}<0,05$ evaluated as significant). Numbers and the percentages of dancers were 2 (7\%), 21 (70\%) and 7(23\%) for RR, RX and XX genotypes, respectively. The same numbers and the percentages were $15(50 \%), 8(15 \%)$ and $7(23 \%)$ for $\mathrm{RR}, \mathrm{RX}$ and XX genotypes, respectively, for the controls. Allele numbers and percentages of the R allele were 38 $(63 \%)$ and $25(42 \%)$ for the control and dancers, respectively. For X allele, the respective number for control and dancers were $22(37 \%)$ and $35(58 \%)$. No significant difference was detected between the groups in the terms of genotypes and alleles. Only RX genotype was significantly different between dancers and non-dancers $(\mathrm{p}<0,05)$. The results of the present and the first study, associating professional dancers and ACTN3 R577X polymorphism, is suggesting that RX genotype may have an genetic advantage for the physical predisposition for dancing, at least in the terms of ACTN3 R577X polymorphism. Prospective studies with extended numbers of dancers focusing on the influence of ACTN3 R577X polymorphism are required for confirmation of these findings.
\end{abstract}

KEY WORDS: Athletic Performance, Dancer, Actinin, PCR, Sport Genetics.

\section{INTRODUCTION}

Dance, in general in different form and its fundamental goals has been recognized as part of national culture in every country. Turkish dance is considered to be one of the liveliest and have colorful themes. Its unique rhetoric includes stories of, ancient Anatolian heroes, Asian shamans, Islamic traditions and westernization.
Belly dance, folk dance, horon and zeybek are some of the famous Turkish dance types. In addition to these, as westernization proceeds, Latin and hip-hop dances are gaining great importance in Turkey.

Dance his also considered to be a branch of art that is allied to music, and to date, there has been little studies conducting dance and

*. Corresponding Author:

Korkut Ulucan

E-mail: korkutulucan@ hotmail.com 
molecular genetics. Aptitude, propensity, motivation and also the physical properties are considered to be the important features of dancers, and these common properties are thought to be the result of genetic endowment. To understand the rhythm and to make the right attempt, dancers should have the right combinations of phenotypes that are influenced by both genes and environmental factors like practicing. Not only have the biological parameters of psychology and cognitive neuroscience, also physical parameters affected dancing activity.

Sports genomics is considered to be a new scientific discipline and it covers all the genetic studies, which are related with the athletic performance and its phenotypes like coordination and flexibility. Angiotensin converting enzyme (ACE) and alpha-actinin-3 (ACTN3) genes are the most examined genetic factors in the terms of endurance and power related phenotypes. As hip-hop and Latin dance are considered to have an aerobic nature, these parameters are involved in dance metabolism. Therefore, it is important to have information about the genetic parameters effecting athletic performance in dance metabolism.

Actinins are actin binding proteins and have important functions in muscle contraction. In humans, 4 types of different actinins exist, and each type is encoded by spesific genes (1). Alphaactinin -3 (ACTN3) is one of the fibrillar actinin proteins encoded by ACTN3, which is commonly expressed in fast twitch fibers and related directly with the structure and function of the muscle fibers. Expression levels of ACTN3 in various athletes and players were examined in order to understand physical performance features based on gene expression level. Before, ACTN3 R577X polymorphism in elite athletes and a direct correlation between ACTN3 R577X allele distribution and performance level was reported (2). The relationship between ACTN3 variants and sprint performance of elite athletes (3) and of middle- school children (4) were also reported. In a study, also ACTN3 genotype and high density lipoprotein-C levels were shown to be related with each other in rugby players (5). The lack of $\alpha$-actinin-3 because of homozygosity for the null ACTN3 577X-allele significantly affects structural performance of muscles in athletes $(6,7)$.

Despite some studies trying to associate the genetic parameters in dancers $(8,9)$, studies including genetic polymorphisms effecting physical properties and professional dancers are very limited. The aim of this study was to determine the genotype and allele distribution of ACTN3 R577X polymorphism in Turkish professional dancers and assess the impact of this polymorphism on dancing activity.

\section{MATERIALS AND METHODS}

Measurement of Fat Oxidation Rate. A total amount of 30 professional dancers and 30 healthy sedentary non- dancer subjects (controls) having no any genetically transmitted disease in their families and first-degree relatives were recruited for the study. Dancers are the ones who are currently performing at least $9 \mathrm{~h}$ per week. Written inform content explaining the study protocol was taken from all participants. The study procedure was followed in according to principles of the Helsinki.

DNA Isolation and Genotyping. Genomic DNA was isolated from $2 \mathrm{ml}$ peripheral blood using the High Pure PCR Template Preparation Kit (Roche, Mannheim, Germany) according to the instructions of the manufacturers provided. ACTN3 R577X polymorphism detection was carried out by using specific four-primer PCR as previously described (10). The superiority of this methodology when compared to other procedures is that, it is possible to detect all genotypes of the related polymorphism just with a single PCR run. The primers used were listed in Table 1 .

\begin{tabular}{|c|c|c|}
\hline \multicolumn{2}{|c|}{ Table 1. Primers for genotyping of ACTN3 R577X polymorphism. } \\
\hline Primer & Sequence (5'-3') & Amplicon length (bp) \\
\hline External forward & CGCCCTTCAACAACTGGCTGGA & \multirow{2}{*}{690} \\
\hline External reverse & GATGAGCCCGAGACAGGCAAGG & \\
\hline Internal forward & CAACACTGCCCGAGGCTGACTG & 318 (with external reverse) \\
\hline Internal reverse & CATGATGGCACCTCGCTCTCGG & 413 (with external forward) \\
\hline
\end{tabular}


Briefly, primers were diluted as 0.125 and $0.25 \mathrm{mM}$ for the internal primers and $0.5 \mathrm{mM}$ for the external primers. In practice, four volumes of external primers, one volume of the forward internal primer, and two volumes of the reverse internal primers were prepared as endues primer solution.

PCR protocol was as follows: $50 \mu \mathrm{l}$ final solution contained $4 \mu \mathrm{l} \mathrm{MgCl}_{2}, 3 \mu \mathrm{l}$ primer mix,
$1 \mu 1$ dNTP mixture, $2.5 \mu 1$ DMSO, $5 \mu 1$ Buffer, 3 $\mu 1$ of prepared primers, $1 \mathrm{U}$ Taq polymerase and $8 \mu \mathrm{l}$ DNA template. The samples were submitted to the following PCR conditions: $95^{\circ} \mathrm{C}$ for $3 \mathrm{~min}$ for predenaturation; 35 cycles at $95^{\circ} \mathrm{C}$ for $20 \mathrm{~s}$ for denaturation, $68^{\circ} \mathrm{C}$ for $30 \mathrm{~s}$ for annealing, and $72^{\circ} \mathrm{C} 1 \mathrm{~min}$ for extension; and a final step of $72^{\circ} \mathrm{C}$ for $5 \mathrm{~min}$. Amplicons were analyzed in $2 \%$ agarose gels (Figure 1).

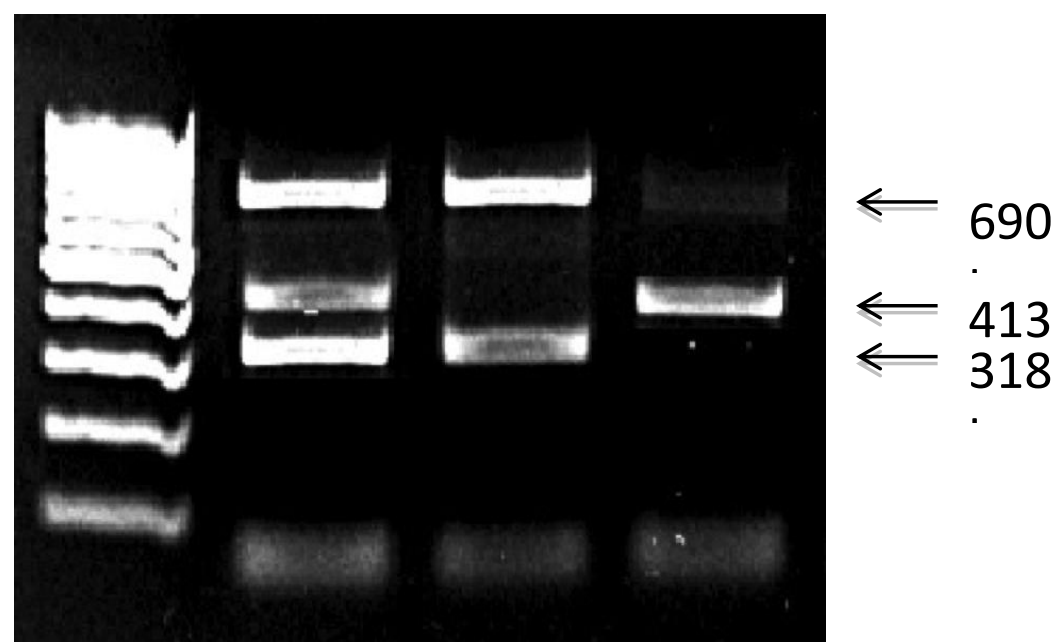

Figure 1. Agarose gel electrophoresis of ACTN3 R577X polymorphism amplification. PCR was performed with two external and two internal primers. The external primers produce 690 bpamplicons for control in all samples. The forward internal primer and the reverse external primer combine to produce a 318-bp amplicon in the presence of $\mathrm{T}$ allele (X genotype). The reverse internal primer and the forward external primer produce a 413-bp amplicon for the $\mathrm{C}$ allele ( $\mathrm{R}$ genotype). The first lane is the $100 \mathrm{bp}$ marker, lane 1 is RX, lane 2 is RR and lane 3 is XX.

Statistical Analysis. SPSS-18.0 (Statistical Package of Social Science version 18.0) was used to evaluate statistical analysis. The differences in allele and genotype frequencies between the groups were evaluated by chi-square test. Allele frequencies were deduced from the direct count of genotypes. Relationships yielding $\mathrm{p}$ values less than 0.05 were evaluated to be significant $(\mathrm{p}<0.05)$, whereas the data having a bigger $p$ value of $0.05(p>0.05)$ evaluated to be non-significant.

\section{RESULTS}

Of the 30 dancers, the numbers and the percentages were $2(7 \%), 21(70 \%)$ and 7 (23\%) for RR, RX and XX genotypes, respectively. For the control group; numbers and the percentages were $15(50 \%), 8(15 \%)$ and $7(23 \%)$ for RR, RX and XX genotypes, respectively. As the ACTN3 R577X genotype is not sex-related, we did not differ sex distribution. When we examine allelic number and frequency, $\mathrm{R}$ allele were counted as 38 $(63 \%)$ and $25(42 \%)$ for the control and dancers, respectively. For $\mathrm{X}$ allele, the respective numbers and the percentages for control and dancers were $22(37 \%)$ and 35 (58\%) (Table 2).

We detected no significant differences between the genotypes of control and dancer groups, except the RX genotype. RX genotype was detected to be as $70 \%$ in dancers, and $15 \%$ in non- dancers, and this results was statistically significant between 
dancers and non- dancers $(\mathrm{p}=0.002)$. No statistically significant difference was detected between the $\mathrm{R}$ and the $\mathrm{X}$ alleles of the two groups.

Table 2. Genotype and allele genotype and frequencies of controls and dancers.

\begin{tabular}{|c|c|c|c|c|c|c|}
\hline & & \multicolumn{3}{|c|}{ GENOTYPE } & \multicolumn{2}{|c|}{ ALLELE FREQUENCY } \\
\hline & & $\mathbf{R R}$ & $\mathbf{R X}$ & $\mathbf{X X}$ & $\mathbf{R}$ & $\mathbf{X}$ \\
\hline \multirow{2}{*}{ CONTROL } & Number & 15 & 8 & 7 & 38 & 22 \\
\hline & Percent & $50 \%$ & $27 \%$ & $23 \%$ & $63 \%$ & $37 \%$ \\
\hline \multirow{2}{*}{ DANCER } & Number & 2 & 21 & 7 & 25 & 35 \\
\hline & Percent & $7 \%$ & $70 \%$ & $23 \%$ & $42 \%$ & $58 \%$ \\
\hline
\end{tabular}

\section{DISCUSSION}

In the examined cohort, RX genotype of ACTN3 R577X polymorphism statistically differed between dancers and non- dancers. No other statistically significant difference detected between genotype-genotype and allelic comparisons. The present report is the first to demonstrate the ACTN3 R577X genotype profiles in Turkish professional hip-hop and Latin dancers. Physical and mental factors play crucial importance in dancing and studies to date accumulate on mental activities about dancers. Dancing activity is considered to have an aerobic performance, extending from minutes to hours, making high-intensity movement such as quick moving, jump, rotation and leap; our findings gave us some evidence about the genetic structure of dancers, at least in the terms of ACTN3 R577X polymorphism.

To date, many studies were carried out in determining ACTN3 R577X polymorphism in different sports types that requires different athletic performance. Most of these studies reported that endurance activities related with $\mathrm{XX}$, sprint/power activities related with RR genotype. Nirengi et al. (2016) analyzed 76 rugby players to determine the association of R577X polymorphism and antiatherogenic markers (high-density lipoprotein cholesterol and adiponectin). In their study, they reported the RX genotype as $39.5 \%$, as the highest genotype percentage in the examined cohort. Rather than trying to explain its role on athletic performance, they tried to associate the polymorphism with the antiatherogenic marker levels (5).

Our study cohort demonstrated the RX genotype as dominating genotype profile. $\mathrm{R}$ allele is considered as the wild type, coding the actin binding protein in type II muscle fibers, whereas $X$ allele leads to a deficiency of the protein. This deficiency disturbs the contractile protein arrangement across multiple contractions involving type 2 muscle fibers (11). But surprisingly, many studies reported that this deficiency was associated with endurance activities, and with aerobic capacity, rather than a disease. In our cohort, RX genotype had the percentage of $70 \%$, and has a statistically significant difference when compared to controls. It is difficult to explain dancing performance and its association with RX genotype, but we may speculate on the advantages of this deficiency. A previous study showed that deficiency in actn 3 protein resulted in increased calcineurin metabolism of skeletal muscle and an enhanced adaptive response to endurance training (12). This finding may help us to explain why $\mathrm{X}$ allele and individuals with $\mathrm{XX}$ or $\mathrm{RX}$ genotype has predisposition to aerobic performance. In other hand, as coding $\mathrm{R}$ allele is enough for rapid contraction and flexibility, for dancers, where advanced movements of whole body is needed, RX genotype may have advantage for dance performance.

Like our findings, Kim et al. (2014) examined the association of body composition, flexibility, and injury risk to genetic 
polymorphisms including $A C E I D, A C T N 3 R X$, and COL5A1 polymorphisms in Korean ballet dancers and reported that ACE ID and ACTN3 RX polymorphisms were related with ballerinas' physical performance. In their study, they analyzed 97 elite ballerinas and 203 controls and showed that $55.7 \%$ of their ballerinas had the RX genotype (8).

Bachner-Melman et al. (2005) genotyped a total of 85 dancers for the serotonin transporter (SLC6A4: promoter region HTTLPR and intron 2 VNTR) and the arginine vasopressin receptor 1a (AVPR1a: promoter microsatellites RS1 and RS3) genes to understand the social communication, courtship, and spiritual facets of the dancing phenotype and reported the importance of the analyzed parameters in dancing activity. Not only the neuro-scientific markers of decision, but also the athletic performance markers are important in dancing, as this activity is a sum of isometric and isotonic muscle contractions. Therefore, it is important to have information about the genetic parameters which influences athletic performance (13).

\section{CONCLUSION}

The main finding of the present study revealed a higher RX genotype in dancer when compared to non-dancer group. A higher RX genotype in Turkish professional dancer tempting us to suggest that this genotype should be taking in consideration for this kind of dance activity in Turkey. Further studies with high magnitude and number sizes are warrant to better understanding of the possible quantity and quality of dancing activity for who are working on this area and physical activity talent. Our results revealed that RR genotype is underrepresented in dancers, and $\mathrm{RX}$ genotype is significantly higher in dancers when compared to non- dancers. We recruited 30 dancers in this pilot study, but to clarify these findings, future analyses with extended numbers of subjects will fulfill the effect of $A C T N 3$ in dance performance.

\section{APPLICABLE REMARKS}

- In dance, not only neuro-scientific markers, but also physical factors are important.

- ACTN3 RX genotype is higher in Latin and hip-hop dancers.

- Genetic counseling depending on genetic polymorphisms will be an informative approach in deciding the dance style.

\section{REFERENCES}

1. Ulucan K. Literature Review of Turkish Sportsmen in Terms of ACTN3 R577X Polymorphism. Clin Exp Health Sci. 2016;6(1):44-7.

2. Peplonska B, Adamczyk JG, Siewierski M, Safranow K, Maruszak A, Sozanski H, et al. Genetic variants associated with physical and mental characteristics of the elite athletes in the Polish population. Scandinavian journal of medicine \& science in sports. 2016.

3. Papadimitriou ID, Lucia A, Pitsiladis YP, Pushkarev VP, Dyatlov DA, Orekhov EF, et al. ACTN3 R577X and ACE I/D gene variants influence performance in elite sprinters: a multi-cohort study. BMC Genomics. 2016;17(1):285.

4. Ulucan K, Bayyurt GM, Konuk M, Güney AI. Effect of alpha-actinin-3 gene on trained and untrained Turkish middle-school children's sprinting performance: a pilot study. Biological Rhythm Research. 2014;45(4):509-14.

5. Nirengi S, Fujibayashi M, Tsuzaki K, Furuno S, Uchibe A, Kawase Y, et al. ACTN3 GENE R577X POLYMORPHISM ASSOCIATED WITH HIGH-DENSITY LIPOPROTEIN CHOLESTEROL AND ADIPONECTIN IN RUGBY PLAYERS. Endocrine practice : official journal of the American College of Endocrinology and the American Association of Clinical Endocrinologists. 2016;22(7):786-90.

6. Broos S, Malisoux L, Theisen D, van Thienen R, Ramaekers M, Jamart C, et al. Evidence for ACTN3 as a Speed Gene in Isolated Human Muscle Fibers. PLoS One. 2016;11(3):e0150594.

7. Hogarth MW, Garton FC, Houweling PJ, Tukiainen T, Lek M, Macarthur DG, et al. Analysis of the ACTN3 heterozygous genotype suggests that alpha-actinin-3 controls sarcomeric composition and muscle function in a dose-dependent fashion. Human molecular genetics. 2016;25(5):866-77. 
8. Kim JH, Jung ES, Kim C-H, Youn H, Kim HR. Genetic associations of body composition, flexibility and injury risk with ACE, ACTN3 and COL5A1 polymorphisms in Korean ballerinas. Journal of Exercise Nutrition \& Biochemistry. 2014;18(2):205-14.

9. Morucci G, Punzi T, Innocenti G, Gulisano M, Ceroti M, Pacini S. New frontiers in sport training: genetics and artistic gymnastics. Journal of strength and conditioning research / National Strength \& Conditioning Association. 2014;28(2):459-66.

10. Schadock I, Schneider A, Silva ED, Buchweitz MR, Correa MN, Pesquero JB, et al. Simple Method to Genotype the ACTN3 r577x Polymorphism. Genetic testing and molecular biomarkers. 2015;19(5):253-7.

11. Roth SM, Walsh S, Liu D, Metter EJ, Ferrucci L, Hurley BF. The ACTN3 R577X nonsense allele is underrepresented in elite-level strength athletes. European journal of human genetics : EJHG. 2008;16(3):391-4.

12. Seto JT, Quinlan KG, Lek M, Zheng XF, Garton F, MacArthur DG, et al. ACTN3 genotype influences muscle performance through the regulation of calcineurin signaling. The Journal of clinical investigation. 2013;123(10):4255-63.

13. Bachner-Melman R, Dina C, Zohar AH, Constantini N, Lerer E, Hoch S, et al. AVPR1a and SLC6A4 Gene Polymorphisms Are Associated with Creative Dance Performance. PLoS Genetics. 2005;1(3):e42. 